\begin{tabular}{|c|}
\hline 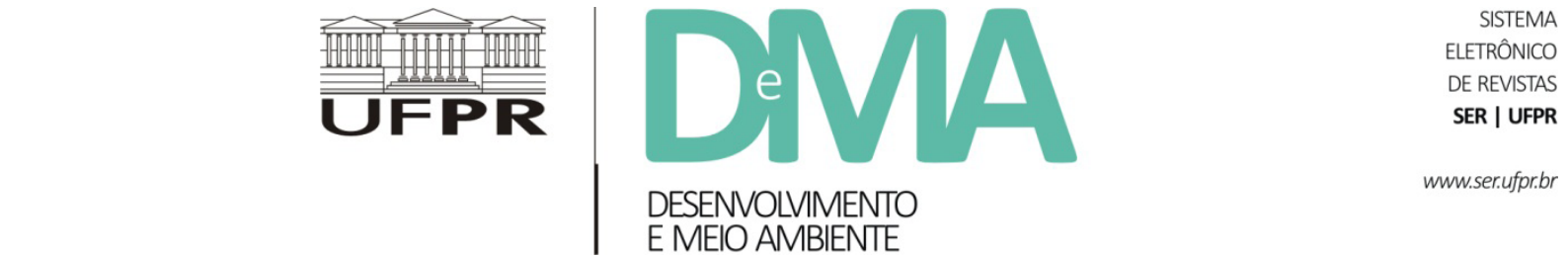 \\
\hline
\end{tabular}

\title{
Os riscos ambientais da indústria de adesivos
}

\section{Environmental Risks of the Adhesive Industry}

\author{
Isabel Valério GONZÁLEZ1 ${ }^{1}$, Haide Maria HUPFFER ${ }^{1 *}$, Vanusca Dalosto JAHNO ${ }^{1}$ \\ ${ }^{1}$ Universidade Feevale, Novo Hamburgo, RS, Brasil. \\ *E-mail de contato: haide@feevale.br
}

Artigo recebido em 16 de janeiro de 2016, versão final aceita em 4 de julho de 2016.

RESUMO: $\quad$ A Lei 12.305/2010 instituiu a Política Nacional de Resíduos Sólidos (PNRS), contribuindo decisivamente para minimizar o volume de resíduos sólidos e rejeitos gerados. O presente estudo propõe uma análise da aplicabilidade da PNRS e do princípio da responsabilidade compartilhada pelo ciclo de vida do produto adesivo, bem como objetiva indicar ações de gestão ambiental preventiva para a indústria de adesivos, mormente na parte contratual, sob a ótica da responsabilidade civil. A pesquisa é qualitativa, utiliza o método indutivo com apoio em pesquisa bibliográfica e documental. Os resultados apontam a relevância da responsabilização ambiental de todos os envolvidos no processo produtivo e de consumo do adesivo. Contudo, restou evidenciada a fragilidade da PNRS em face do risco abstrato. Por fim, apontam-se ações de gestão ambiental preventiva, dando ênfase à inclusão de cláusulas ambientais nos contratos jurídicos celebrados pela indústria de adesivos com seus fornecedores, parceiros e clientes.

Palavras-chave: adesivo; ciclo de vida do produto; gestão ambiental preventiva; Política Nacional de Resíduos Sólidos; responsabilidade compartilhada.

ABSTRACT: The Law 12.305/2010 created the National Politics for Solid Waste (NPSW), decisively contributing towards the minimization of solid waste and residue volumes generated. The present study proposes an analysis of the applicability of the shared responsibility principle for the life cycle of the product adhesive, as well as intends to indicate preventive waste management actions for the adhesive industry, moreover in the contractual part under the optics of civil responsibility. The research is qualitative and uses the inductive method supported by bibliography and documental research. The results point out the relevance of environmental responsibility of all the parties involved in the productive and consumer process of the adhesive. However, evidence showed the fragility of NPSW due to the abstract risk. Lastly, preventive environmental management actions are indicated, with emphasis to the inclusion of contractual environmental clauses in the legal contracts celebrated by the adhesive industry with its providers, partners and clients.

Keywords: adhesives; life cycle of the product; preventive environmental management; National Politics for Solid Waste; shared responsibility. 


\section{Introdução}

A Política Nacional de Resíduos Sólidos PNRS (Lei 12.305/2010) foi instituída após mais de vinte anos de trâmite no Congresso Nacional com o intuito de sanar a grave situação dos resíduos que assola a sociedade brasileira. A PNRS traz diversos princípios e ações de gestão e de gerenciamento de resíduos que devem ser observados pelas áreas pública e privada. Dentre os principais preceitos trazidos pela PNRS está o princípio da responsabilidade compartilhada pelo ciclo de vida dos produtos, previsto no art. $6^{\circ}$, VII, segundo o qual todos os envolvidos na produção e no consumo de produtos são solidariamente responsáveis pelo manejo dos resíduos gerados nesse processo. Este princípio é de fundamental importância para o gerenciamento efetivo de resíduos. Daí exsurge a necessidade de as indústrias de adesivos estabelecerem ações específicas de gestão ambiental preventiva no que concerne à disposição desse resíduo, adaptando suas relações jurídicas a essas ações ambientais, mormente às obrigações legais de responsabilidade compartilhada pelo ciclo de vida do produto.

$O$ presente estudo pretende analisar a efetividade do princípio da responsabilidade compartilhada pelo ciclo de vida do produto, previsto no art. 30 da PNRS, sob um enfoque voltado propriamente para o risco abstrato, uma vez que a lei ainda é vaga no que se refere a resíduos intangíveis, ficando a utilização e o descarte desses materiais às margens da lei.

Como objeto, utilizar-se-á uma área geradora de resíduos não tão visível como as de costume: a indústria de adesivos. Esse ramo industrial é de extrema importância devido ao seu alcance, uma vez que fornece para as indústrias calçadista, moveleira, de construção civil, de cosméticos, de saúde e higiene, automotiva, dentre outras. Outros aspectos a considerar estão na relevância ambiental de seus produtos, seu amplo potencial poluidor, abstração do resíduo ao integrar outros produtos, bem como o seu destaque nos mercados nacional e internacional.

A pesquisa apresenta caráter teórico-reflexivo e segue um caminho dedutivo, partindo de contextualizações gerais para o caso particular da indústria de adesivos. Envolve uma revisão bibliográfica e documental acerca dos conceitos de sociedade de risco, incerteza científica, risco abstrato, ciclo de vida do produto, a Política Nacional de Resíduos Sólidos e outras importantes leis e documentos que tratam da responsabilidade ambiental pelo ciclo de vida do produto e da responsabilidade compartilhada. A dialética está presente na pesquisa quando se examina a literatura especializada sobre a produção dos resíduos da indústria de adesivos e seus riscos ao meio ambiente, tanto no processo de produção como na utilização do adesivo, bem como no momento pós-consumo, com uma crítica à efetividade de certas ações em razão das características do produto, bem como com a indicação final de práticas ambientais sustentáveis como medidas de gestão ambiental preventiva para a indústria de adesivos.

\section{Risco abstrato e o ciclo de vida do produto na Política Nacional de Resíduos Sólidos}

A sociedade pós-moderna não consegue mais antever os riscos do setor produtivo devido aos avanços da ciência e da tecnologia. Esse conceito se traduz na denominada sociedade de risco, a qual, por sua vez, deu à luz a Teoria do Risco Abstrato, na qual a sociedade, por meio da sua evolução tecnológica, torna-se um risco para si mesma, devido aos avanços da ciência (Beck, 1998, p. 36). Corolários da Teoria da Sociedade de Risco, os conceitos de 
risco abstrato e de dano futuro representam perfeitamente o dilema dos resíduos provenientes da produção moderna, pois refletem a invisibilidade, a globalidade e a transtemporalidade do dano e do risco inerentes às novas tecnologias.

Os riscos abstratos carregam em si potenciais de autodestruição civilizatória que escapam à percepção humana imediata, desencadeando danos invisíveis que levam a situações sociais de ameaça. O conhecimento sobre riscos e seus efeitos na saúde humana e no meio ambiente adquire uma nova relevância política, visto que os intrincados caminhos de seus efeitos nocivos são incalculáveis, imprevisíveis e de alcance mundial. Consequentemente, a "esfera pública e a política passam a reger a intimidade do gerenciamento empresarial" no processo produtivo, na disposição final dos resíduos, nos equipamentos técnicos e na responsabilização pelos danos e riscos resultantes da atividade. A prevenção de riscos e seu manejo reorganizam o poder e a responsabilidade (Beck, 2010, p. 27-33).

A incerteza científica em que estão imersos os riscos abstratos do processo produtivo é agravada pelo fato de o Estado e de uma parcela de empresas utilizarem "meios e instrumentos para ocultar as origens e os efeitos do risco ecológico, com o objetivo de diminuir suas consequências, ou melhor, com o fim de transmitir para a sociedade uma falsa ideia de que o risco ecológico está controlado" (Leite \& Belchior, 2012, p. 16) ou será controlado quando da aprovação de novas tecnologias. O mais grave é que o risco abstrato, pela sua invisibilidade e imprevisibilidade, tem potencial de atingir as gerações presentes e futuras, em uma escala temporal e espacial inimaginável e de difícil determinação pelo conhecimento humano (Leite \& Ayala, 2004).

Em relação ao setor produtivo, tem-se por notório que diferentes componentes possuem diferentes tratamentos por seus produtores, haja vista sua natureza. Nesse sentido, merecem destaque componentes que tornam o produto final e, consequentemente, seu resíduo nocivos ao meio ambiente, gerando os chamados riscos abstratos. As teorias modernas de dano futuro e risco abstrato traduzem perfeitamente a questão, pois destacam que alguns dos efeitos de produtos modernos sobre o corpo humano são intangíveis e somente poderão ser confirmados com o tempo. Por isso, a importância da Política Nacional de Resíduos Sólidos (PNRS) sobre a responsabilidade pelo ciclo de vida do produto, que serve de pano de fundo para alertar sobre os riscos e perigos do produto adesivo.

A noção de ciclo de vida dos produtos não é novidade para a biologia. Carson (1962, p. 15) já destacava o perigo de utilização de agentes químicos ao afirmar que "nesta contaminação, agora universal, do meio ambiente, as substâncias químicas são parceiros sinistros e pouco reconhecíveis das radiações na tarefa de modificação da própria natureza do mundo". Segundo a autora, as substâncias químicas utilizadas na época para cultivo (pesticidas) passavam "misteriosamente" de uma área para outra, contaminando o solo, a água e o ar (Carson, 1962, p. 16).

Diante do cenário atual de abstração do risco dos agentes (químicos e físicos) utilizados pelas novas tecnologias, é de suma relevância a definição de ciclo de vida dos produtos para que se possa ter alguma forma, ainda que não totalmente precisa e eficaz, de responsabilização pelos efeitos da utilização de tais produtos na natureza.

A definição do ciclo de vida do produto é matéria tecnicamente complexa e extremamente abrangente, pois envolve a elaboração sintética de substâncias produzidas em laboratórios e que não possuem "contrapartes" na natureza (Carson, 1962, p. 17), englobando ainda (num conceito mais 
moderno) todo o fluxo de materiais e energia envolvidos em todas as etapas de fabricação do produto e sua distribuição. Assim, devem ser consideradas as etapas de: extração da matéria-prima, transporte para fabricação, produção, transporte de distribuição, uso, fim de vida e embalagem (EC, 2010).

$\mathrm{Na}$ prática científica, utiliza-se a Avaliação do Ciclo de Vida - ACV, padronizada pela International Organization for Standardization - ISO, por meio da Norma 14040, e sua série, que visa determinar os aspectos ambientais e impactos de um produto ou serviço durante todo o processo de fabricação, consumo e disposição final. Segundo essa norma, para a ACV é necessário um diagnóstico de todos os processos de entrada e saída de produtos e materiais ao longo da cadeia produtiva, inclusive aqueles utilizados indiretamente, como água, luz e energia, com análise de escopo, inventário, impactos e resultados. A ACV deve servir de base para a implantação do Sistema de Gerenciamento Ambiental - SGA, instituído pela Norma ISO 14001/2015 e sua série, que regula a obtenção dos selos verdes e declarações ambientais. Essa norma foi recentemente revisada justamente para detalhar os processos de gerenciamento do risco ambiental, reduzir o consumo de recursos naturais e baixar os custos operacionais das indústrias, visando assim contemplar o ciclo de vida na certificação ambiental. (ABNT, 2015).

Na visão de Pinz (2012, p. 179), é importante incorporar a análise de ciclo de vida dos produtos ao processo de licenciamento de forma a "minimizar o impacto ambiental da inserção do bem no mercado", bem como considerar, desde a concepção de um produto, os materiais a serem utilizados, o volume destes, a forma de consumo, a durabilidade e as embalagens com base nas diretrizes de "não geração, redução, reutilização, reciclagem e disposição final adequada". Há alguns anos já se tem, principalmente em nível internacional, meios tecnologicamente avançados para avaliação de $\mathrm{ACV}$, inclusive com a utilização de software de gestão (Juarez et al., 2008).

APNRS introduziu pela primeira vez, na legislação, o conceito de ciclo de vida do produto: "série de etapas que envolvem o desenvolvimento do produto, a obtenção de matérias-primas e insumos, o processo produtivo, o consumo e a disposição final" (Milaré, 2013, p. 213). Nos termos do art. $3^{\circ}$, inciso XVII, da Lei 12.305/2010, a responsabilidade compartilhada por todo o ciclo vital dos produtos consiste no conjunto de atribuições individualizadas e encadeadas dos fabricantes, importadores, distribuidores e comerciantes, dos consumidores e dos titulares dos serviços públicos de limpeza urbana e de manejo dos resíduos sólidos, para atenuar a quantidade de resíduos sólidos e rejeitos gerados, e reduzir os impactos causados à saúde humana e à qualidade ambiental decorrentes do ciclo de vida dos produtos (Milaré, 2013, p. 213). Sobretudo, a Avaliação do Ciclo de Vida (ACV) tem o papel de diagnosticar os processos de produção e consumo que menos impactam na qualidade ambiental, permitindo, assim, maior eficiência no uso de recursos e menos impacto no meio ambiente.

Assim, tem-se que a adoção da ACV é uma ferramenta científica imprescindível para o desenvolvimento sustentável, haja vista que é essencial para a avaliação de geração de impacto ambiental, mormente para a geração de resíduos, servindo de suporte a decisões gerenciais ao identificar os custos, riscos e benefícios dos processos de produção e consumo de energia e materiais visando à produção sustentável, seja por meio da redução do consumo, seja pela reutilização. O uso da ACV também torna possível a avaliação dos benefícios e custos no que se refere a estratégias que envolvam a geração de resíduos, permitindo a tomada de decisão para o 
melhor resultado ambiental. Não obstante, como relatam Hauschild et al. (2013), ainda não há um consenso com relação à padronização dos métodos de avaliação do ciclo de vida dos produtos, haja vista a variedade de métodos de avaliações e de produtos existentes no mercado.

No Brasil, devido às exigências da legislação ambiental, o enfoque dos estudos e processos do ciclo de vida dos produtos se dá, prioritariamente, com relação ao impacto ambiental, como relatam Willers \& Rodrigues (2014). Nacionalmente, a comunidade científica ainda carece do estabelecimento de processos estritamente voltados para a ACV e de normatização dos processos industriais, como existem em nível internacional.

Por outro lado, cabe retomar a peculiaridade inerente ao produto adesivo em se integrar aos demais produtos para os quais se destina. Em outras palavras, o adesivo, ao ser aplicado em um papelão, um móvel de madeira, uma peça de carro, um solado de calçado, adere a este objeto de forma que só pode ser removido mediante um processo mecânico ou químico. Em vista disto, o tratamento, a disposição final e a destinação dos produtos aos quais são aplicados adesivos tornam-se ainda mais complexos, pois atualmente não existe uma preocupação em separar e destinar corretamente todos os materiais que usam adesivos em sua composição. Existe, sim, esta preocupação dos órgãos regulamentadores em dispor corretamente os resíduos finais, mas apenas em alguns casos, como os calçados ou peças de carros. Porém, esta preocupação não decorre exclusivamente do fato de possuírem adesivos em sua composição, mas por terem outros componentes que requerem atenção especial quando da destinação final, como todo o tratamento químico que envolve o couro e demais componentes de um calçado, ou, ainda, a composição de termoplásticos de uma peça de automóvel.
Logo, para se obter de fato uma destinação final adequada de resíduos, é imprescindível que haja uma avaliação mais abrangente da composição dos produtos e do seu ciclo de vida.

\section{A responsabilidade compartilhada pelo ciclo de vida do produto}

O Direito Ambiental Brasileiro assumiu o princípio da responsabilidade objetiva pelo dano ecológico, bastando para a sua consolidação o dano e o nexo causal, como se denota do art. 14 da PNMA. A Constituição Federal recepcionou essa posição em seu art. 225, § $3^{\circ}$ (Brasil, 1988). O Direito Civil pátrio também adota a responsabilidade objetiva por dano, que está refletida no Código Civil, art. 927. De acordo com o art. 942 do Código Civil, a responsabilidade civil é solidária, englobando todos os envolvidos de alguma forma na ação ou omissão (Brasil, 2002). Esses preceitos aplicam-se subsidiariamente ao Direito Ambiental, tendo-se, portanto, que a responsabilidade civil por dano ambiental é objetiva e solidária.

A objetividade e a solidariedade da responsabilidade por dano ambiental decorrem da dificuldade de apuração da conduta causadora do dano e provável multiplicidade de agentes, sendo essencial para a garantia da responsabilização por dano ambiental (Steigleder, 2011). Afinal, o dano ambiental é impessoal, não tendo como sujeito passivo uma vítima específica, mas sim diversas, como toda uma comunidade afetada pela contaminação de sua água ou ar. Assim, basta a simples existência de atividade possivelmente danosa e o dano para que se configure, perante o Direito, a responsabilidade (Milaré, 2013). É a adoção da Teoria do Risco Integral, pela qual "todo e qualquer risco conexo ao empreendimento deverá ser integralmente internalizado pelo 
processo produtivo, devendo o responsável reparar quaisquer danos que tenham conexão com sua atividade" (Steigleder, 2011, p. 198).

O princípio da responsabilidade compartilhada pelo ciclo de vida dos produtos está fundado na responsabilidade objetiva prevista inicialmente na legislação pátria na Lei da Política Nacional do Meio Ambiente - PNMA (Lei n. 6.938/81), em seu art. $14, \S 1^{\circ}$, que dispõe que a não observância das medidas de preservação ou correção de inconvenientes ou danos por degradação ambiental implicará na aplicação de penalidades como multa, perda de direitos a incentivos fiscais e linhas de financiamentos oficiais de crédito, suspensão da atividade, bem como ação judicial por responsabilidade civil e criminal, independentemente da perquirição de culpa. Logo, a PNMA (Lei n. 6.938/81) serviu de norte para a elaboração da PNRS. Adicionalmente, a PNMA prevê, em seu artigo $3^{\circ}$, IV, a responsabilidade direta e indireta por atividades ambientalmente degradantes (Brasil, 1981). Como já referenciado, a responsabilidade ambiental, além de ser objetiva, é solidária, conceito, portanto, existente na legislação ambiental antes mesmo da promulgação da PNRS e da Constituição Federal de 1988.

A Política Nacional do Meio Ambiente, no inciso IV do art. $3^{\circ}$, já previa a responsabilidade por atividades ambientalmente degradantes, adotando o princípio do poluidor-pagador ao estabelecer o dever de recuperar e/ou indenizar os danos ambientais causados (Lei n. 6.938/81, art. $4^{\circ}$, inciso VII). A Constituição Federal, por sua vez, recepcionou esses princípios consolidando, ainda, o princípio de intervenção estatal na defesa do meio ambiente.

Um dos principais instrumentos para a concretização da gestão ambiental e prevenção de resíduos, a responsabilidade pós-consumo pode ser considerada como "ferramenta de conciliação entre o desenvolvimento e a preservação do meio ambiente" e que apenas mediante a responsabilização civil será possível tratar o "ciclo de vida do resíduo do berço ao berço" (Saldanha, 2012, p. 149). O risco e seu gerenciamento são prioritários na definição de responsabilidades e na adoção de medidas preventivas (Carvalho, 2012).

É imprescindível o alargamento da responsabilidade dos produtores e de todos os envolvidos no processo produtivo de adesivos e no processo de incorporação dos adesivos em outros produtos para consumo, levando em conta todas as fases da produção, desde a concepção dos produtos, a produção e a gestão de seus resíduos, para que um dia seja possível se falar em produção e desenvolvimento sem se falar em reparação de danos, bem como se falar em ciclo de vida de berço a berço e não do berço ao túmulo.

O princípio da responsabilidade compartilhada pelo ciclo de vida do produto é de suma importância para a concretização dos princípios ambientais, sobretudo diante da prevalência inegável do interesse econômico para o setor produtivo. Somente através da responsabilização efetiva é que será possível a realização do ideal de desenvolvimento sustentável como o desenvolvimento de tecnologias mais limpas, redução do consumo de recursos naturais e tantas outras medidas essenciais para a preservação ambiental.

Para a concretização da proteção ambiental, é essencial a adoção de uma gestão ambiental preventiva que vise ao conceito de desenvolvimento sustentável, segundo o qual é imprescindível o comprometimento com a possibilidade de gerações futuras atenderem suas próprias necessidades. Não se pode mais admitir que a tecnosfera prevaleça sobre a biosfera, como tem se visto, sob pena de comprometimento ainda mais grave da sociosfera. Como bem estabelece a PNRS, por meio do princípio da responsabilidade compartilhada, as empresas 
(geradoras de resíduos nos termos da própria PNRS) precisam se comprometer com a integralidade do ciclo de vida de seus resíduos, pois os referidos meios precisam coexistir em harmonia. Em última análise, cuidar do meio ambiente é primordial para a própria sobrevivência da humanidade, o que só se concretizará com a adoção de práticas de gestão ambiental de forma preventiva e que considerem o futuro e a intangibilidade/abstração dos riscos. Como alerta Beck (1998), trata-se de remover as causas ou lutar contra os sintomas.

\section{Os riscos ambientais dos resíduos da indústria de adesivos}

A PNRS constituiu um marco para a mudança no cenário industrial no que tange a resíduos. O legislador optou por definir o termo resíduo conforme sua origem e periculosidade, levando em conta as características de seus elementos, a possibilidade de destinação final (reutilização, reciclagem, compostagem, recuperação, aproveitamento, entre outros) ou a disposição final ambientalmente adequada. No que se refere à origem, a PNRS, em seu art. 13, classifica os resíduos como urbanos - domiciliares e de limpeza urbana-, comerciais e de prestadores de serviços, os de saneamento básico, os industriais, de saúde, da construção civil, os agrossilvopastoris, de transporte e de mineração. Quanto à periculosidade, a PNRS distingue os resíduos entre perigosos, que são os inflamáveis, corrosivos, reativos, tóxicos, patogênicos, carcinogênicos, teratogênicos, mutagênicos e todos que representam risco à saúde ou à qualidade ambiental e que assim sejam considerados por lei, regulamento ou norma. Já os resíduos não perigosos são, por exclusão, os que não se enquadram na definição de perigosos.

A PNRS diferencia também os resíduos de acordo com o tipo: recicláveis (papel, metal, plásti- co, vidro, etc.) e não recicláveis (rejeitos e contaminados), como se denota das definições de destinação e disposição final contidas no art. $3^{\circ}$ da lei.

Os resíduos ainda podem ser classificados de diversas outras formas, como em relação a sua composição química, física e biológica. Nessa classificação, os resíduos são divididos em orgânicos e inorgânicos. Os orgânicos são restos de alimentos, esterco, papel, madeira, e geralmente são passíveis de compostagem. Já os resíduos inorgânicos são plásticos, metal, vidro, borrachas, dentre outros. Importante salientar que os resíduos orgânicos podem ser tóxicos, sendo classificados quanto a esta característica como poluentes orgânicos persistentes (POP) e não persistentes. São, portanto, resíduos provenientes de inúmeros processos, podendo-se citar como exemplos corriqueiros óleos biodegradáveis e detergentes (Brasil, 2010).

Ainda nesta linha, de suma relevância para a definição de resíduos é a relação destes com a fase do processo de produção. Para tanto, considera-se o processo de produção como um todo, levando em conta todas as fases do fluxo de materiais que estão englobados na produção, vez que praticamente em todas as fases e tipos de produção existe geração de resíduos. Assim, desde a fase de extração de matéria-prima, processamento, manufatura, distribuição e logística, há geração de resíduos, como destacam as normas de certificação ambiental mencionadas. Também em todas as fases da produção há consumo de energia, insumos e matéria-prima, cujos processos, por sua vez, também geram resíduos, que devem ser igualmente reaproveitados e tratados a fim de minimizar o impacto ambiental (Baumann et al., 2002). Este é o moderno conceito de sustentabilidade, segundo o qual resíduos são definidos como matéria-prima e insumos não convertidos em produto, e, portanto, sua geração representa perda de lucro para a produção. Destarte, 
a diminuição de perdas no processo produtivo ou o reaproveitamento de resíduos se traduz não só em produção sustentável, mas também lucrativa.

Do mesmo modo, é preciso diferenciar rejeitos de resíduos. Rejeitos são aqueles produtos ou materiais que já esgotaram qualquer possibilidade de tratamento ou recuperação, sendo apenas passíveis de disposição final adequada. Esta, por sua vez, resume-se na distribuição ordenada em aterros, a fim de minimizar os riscos de impacto ambiental. Já os resíduos são as substâncias, materiais ou objetos que podem ser sujeitos à destinação final, ou seja, reutilização, reciclagem, compostagem, recuperação e reaproveitamento (Pinz, 2012).

Assim, a definição de resíduo, com sua devida classificação, é etapa fundamental para determinar sua destinação ou disposição. Portanto, de suma importância para o gerenciamento sustentável, sendo imprescindível a cooperação das diversas áreas cientificas envolvidas neste processo, desde a química até o direito, tornando imperioso esse enfoque multidisciplinar para uma gestão de resíduos eficaz.

Adesivo, como afirma Silva (2008, p. 5), "é um material capaz de manter materiais unidos por interação superficial, oferecendo resistência à separação". Trata-se de material capaz de juntar, colar, unir outros materiais, seja por ligações químicas, forças intermoleculares e/ou ancoragem mecânica. Exemplos corriqueiros são todos os tipos de colas, cimentos, pastas e selantes (Marques, 2009, p. 4).

Os adesivos possuem diversas funções e composições diferentes, sendo utilizados em larga escala nos processos de produção. Para elucidar, pode-se citar sua utilização em diversas indústrias: moveleira (para colar madeira), metal, tecidos e espumas; na indústria de calçados (para colagem de solados); na automobilística e aeroespacial (para colagem de peças, revestimento e para isolamento); na colagem de todos os tipos de embalagens, sejam elas de papel, papelão, plástico, metal ou vidro; na medicina (para curativos e, inclusive, com o auxílio da nanotecnologia, em adesivos cirúrgicos utilizados na pele humana para substituir suturas convencionais) (Oliveira et al., 2010).

$\mathrm{O}$ adesivo é, portanto, uma forma de fixação de materiais que apresenta inúmeras vantagens sobre outras formas, como a fixação mecânica, pois possibilita maior uniformidade na distribuição de tensão, resistência, praticidade, leveza e bom isolamento térmico, dispensando técnicas perigosas e dispendiosas, como a soldagem. Em vista disto, os adesivos têm, cada vez mais, substituído as formas de fixação mecânica de peças nos diferentes tipos de produção (Oliveira et al., 2010).

A indústria de adesivos possui uma imensidade de produtos elaborados com os mais diversos componentes. Os principais componentes dos adesivos são "polímero base, catalisador, solvente (adesivos em solução), aditivos e outros" (Silva, 2008). Ainda, os adesivos podem ser classificados de diversas formas, principalmente por sua composição (base solvente ou água) e origem (natural ou sintético), ou ainda com relação a seu estado físico (líquido ou sólido), base que o compõe (polímero base), finalidade, meio em que é dissolvido, tipo de adesão ou cura (secagem, emulsão, PSA, contato, térmicos, reativos), forma física (filme, pó, pasta, líquido, etc.), dentre outros. Os adesivos com base solvente são os predominantes no mercado desde o século passado, enquanto que os adesivos à base de água são os mais modernos em termos ecológicos. Uma das principais divisões entre os tipos de adesivos, na atualidade, se dá entre os que são à base de água e os à base solvente. Sem dúvida, é crescente a demanda para adesivos à base de água, devido à regulamentação ambiental e à consequente necessidade de diminuição da utilização de recursos 
naturais não renováveis ou de difícil renovação, como petróleo e borracha, bem como pela restrição ao uso de produtos agressivos ao meio ambiente, como solventes utilizados na fabricação de boa parte dos adesivos. Portanto, ambientalmente, os adesivos à base de água são os mais indicados quando se refere à sustentabilidade. Contudo, ainda não há tecnologia que garanta seu uso em todas as áreas, em vista da aderência necessária que, em muitos casos, só é garantida pelo uso de solvente (Marques, 2009).

Em suma, a produção de adesivos, devido à sua ampla composição, ainda representa um risco significativo para o meio ambiente, seja durante o processo de produção, seja na utilização do adesivo, ou, ainda, no momento pós-consumo. A avaliação dos resíduos gerados na indústria química é dificultada pela quantidade de substâncias utilizadas na produção, tornando a avaliação do ciclo de vida dos produtos e, por conseguinte, da toxicidade e da ecotoxicidade de seus resíduos, insuficiente para um resultado satisfatório quanto à preservação do meio ambiente (Hauschild et al., 2013).

Para fins de relacionar apenas alguns dos milhares de resíduos provenientes dos adesivos, convém, primeiro, classificá-los conforme sua composição. Para tanto, os adesivos podem ser considerados orgânicos (possuem em sua estrutura átomos de carbono, além de outros átomos que designam um organismo vivo, como oxigênio, hidrogênio, nitrogênio) ou inorgânicos (são estruturas que não possuem átomo de carbono organizado em cadeia em sua formação, podendo ser ácidos, bases, sais e óxidos). Os adesivos orgânicos são divididos em sintéticos e de origem natural. Os sintéticos são derivados de variados tipos de estruturas químicas. Os principais exemplos são os fenólicos (à base de fenol e formaldeído), copolímeros etileno - conhecidos como hot melt de EVA -, poliacetato de vinila, epóxis, acrílicos, poliamida, poliéster, silicone, cianoacrilato, poliuretânicos e borracha natural. Os de origem natural são, por exemplo, os de colágeno, caseína, albumina, celulose e amido. Os inorgânicos são os silicados e cimentados (Marques, 2009).

Os adesivos sintéticos, devido à sua composição ser constituída de diversas reações químicas, representam maior risco de contaminação ao meio ambiente, enquanto que os adesivos de origem natural, por sua composição, não representam maiores perigos ao meio ambiente. Contudo, a produção de qualquer dos tipos de adesivo e a sua utilização envolvem diversas reações químicas, bem como a utilização de inúmeros componentes em sua produção. Por isso, constituem-se em produtos altamente perigosos para o meio ambiente, pois podem contaminar a água, o solo e o ar, representando um risco para o meio ambiente e para a saúde. Seus resíduos normalmente são resinas, óxidos e solventes (Paiva, 2009) que representam risco de contaminação ao meio ambiente, podendo ser, inclusive, cancerígenos, patogênicos, teratogênicos ou mutagênicos.

Importante salientar que, diante da expansão de indústrias como a automobilística e a aeroespacial e da crescente utilização de peças de polímeros ao invés de metais, é crescente também a demanda por adesivos com base solvente, considerando sua maior pegajosidade (tack) e suas características, tais como propriedades mecânicas e térmicas, capazes de dissipar vibrações e isolamento. Adesivos à base de poliuretanos dispersos em água são o principal tipo utilizado pelas indústrias automotivas, de calçados e de construção, dentre outras (Marques, 2009).

Um dos principais componentes e, por sua vez, principal resíduo proveniente do processo de fabricação do adesivo, é o poliuretano. Esse resíduo pode ser à base solvente ou água. Com o aumento da regulação de resíduos no âmbito mundial e a crescente preocupação com Produção Mais Limpa, cada vez mais a indústria tem buscado alternativas de 
componentes menos poluentes para seus produtos, visando atender o disposto nas normas ambientais. A legislação, ao responsabilizar o empreendedor pela produção de resíduos, está sendo fundamental para mudar a atitude empresarial no sentido de desenvolver poliuretanos cada vez menos tóxicos e poluentes, a exemplo dos com base em água, "já que sua presença e importância na vida cotidiana são bastante significativas" (Carson, 1962, p. 15).

\section{Por uma gestão ambiental preventiva na indústria de adesivos}

Uma das principais características dos adesivos é que eles passam a integrar o produto para o qual são utilizados, como uma peça de carro, um móvel, um calçado. Por outro lado, os adesivos são uma fonte de conflitualidade por envolverem danos e riscos ambientais. O principal risco ambiental apresentado pelos resíduos que contenham adesivos ocorre no caso de descarte indevido do produto final, podendo-se contaminar o meio ambiente por meio da liberação desses resíduos.

Como já observado, tanto os insumos comprados pelas empresas de adesivos (petróleo, acetona, solventes, látex, borracha seringueira) como os produtos desenvolvidos por elas são, na sua maioria, altamente poluentes. De acordo com o disposto na PNRS, o processo de produção das indústrias deve ser desenvolvido com os menores impactos à saúde humana e à qualidade ambiental, estando incluídos nessa responsabilidade todos os agentes envolvidos nos processos de produção, distribuição e consumo. Por força desta lei, é imprescindível a adoção de medidas de gestão ambiental preventiva por parte das empresas de adesivos, afinal, qualquer produto que utilize adesivo com potencial poluente representa responsabilidade ambiental para o produtor em face da PNRS, seja este produto um calçado, um sofá, um carro ou um prédio. De igual modo, a indústria tem responsabilidade em desenvolver tecnologias que possibilitem a utilização de produtos para a composição dos adesivos que diminuam os riscos à saúde e ao meio ambiente, o que representa um importante ganho ecológico, como é o caso dos adesivos à base de água, cujo mercado vem aumentando consideravelmente.

Diante da responsabilidade compartilhada imposta pela PNRS, a indústria de adesivos deve adotar medidas que efetivamente minimizem o volume de resíduos sólidos e rejeitos gerados e que reduzam os impactos causados à saúde humana e à qualidade ambiental, decorrentes do ciclo de vida dos produtos, como substituição por componentes menos poluentes, diminuição da utilização de fontes não renováveis e informação quanto aos meios de disposição final de produtos que contenham adesivos. Afinal, a não observância do ciclo de vida dos adesivos tem sérias consequências sobre o meio ambiente e a qualidade de vida das comunidades afetadas pela produção em questão.

Com este condão preventivo, a PNRS (art. $8^{\circ}$, III) se destaca, ainda, por trazer o instrumento da logística reversa como principal ferramenta para a implementação da responsabilidade pelo ciclo de vida dos produtos. A logística reversa é, segundo o inciso XII do art. $3^{\circ}$ da PNRS:

[...] instrumento de desenvolvimento econômico e social caracterizado por um conjunto de ações, procedimentos e meios destinados a viabilizar a coleta e a restituição dos resíduos sólidos ao setor empresarial, para reaproveitamento, em seu ciclo ou em outros ciclos produtivos, ou outra destinação final ambientalmente adequada.

Este instrumento se traduz na responsabilidade pós-consumo (Pinz, 2012), pois consiste na reutili- 
zação de materiais no processo de produção visando ao desenvolvimento sustentável. Esta prática não é novidade no mercado, afinal, há algumas décadas, as pessoas costumavam retornar as garrafas de leite para serem reutilizadas, por exemplo. O que ocorre, porém, é que atualmente existe uma geração excessiva de resíduos recicláveis provenientes do aumento de produtos e do consumo desenfreado. Contudo, a reutilização trazida pela PNRS se desdobra em diversas formas de reaproveitamento de materiais, como recuperação, reuso, reciclagem (Srivastava, 2007), conforme destacam Souza et al. (2013) em seu estudo sobre o tema da logística reversa.

A logística reversa pode se referir tanto a embalagens utilizadas no processo de distribuição como ao produto em si. Em se tratando de embalagens, cabe a reutilização e posterior reciclagem, seja o caso de plástico, papelão, vidro, metal ou outro. Entretanto, no que se refere ao retorno do resíduo em si ao processo produtivo, ainda há muito a ser detalhado pela literatura, pois há uma variedade infinita de produtos no mercado que são passíveis de reaproveitamento. A reciclagem per se ainda está muito limitada a fatores econômicos, assim como a remanufatura, que é a integração de reciclados no processo da manufatura, como no caso dos automóveis e eletrônicos, vez que o sistema de logística reversa representa $95 \%$ do custo de reciclagem do produto (Srivastava, 2007), onerando muito o processo.

Logo, a logística reversa é uma das principais ferramentas da responsabilidade compartilhada pelo ciclo de vida do produto, fazendo-se necessária para efetivação do desenvolvimento sustentável, apesar do custo atual de sua implementação, na maioria dos casos. Não há dúvida de que os benefícios dessa prática, tanto os econômicos como ambientais, farão com que sua adoção se dê em larga escala futuramente.
Da racionalidade destes conceitos com o restante da lei, é possível afirmar que toda ação cujo intuito seja o de eliminar danos à qualidade ambiental pode ser considerada uma ação de gestão ambiental preventiva. Saldanha (2012, p. 117) destaca que "a gestão ambiental empresarial, na realidade, trata da concretização, bem como da materialização da função socioambiental da atividade econômica [...]". Segundo o autor, dentre as medidas necessárias para o desenvolvimento sustentável, encontram-se obrigatoriamente práticas como a implantação de Sistema de Gestão Ambiental - SGA, com a adoção de análises, metas e métodos, bem como a produção mais limpa $(\mathrm{P}+\mathrm{L})$, que busca a prevenção quantitativa na utilização de materiais, na geração de resíduos ou ainda na prevenção qualitativa (Saldanha, 2012). Afinal, não é possível vislumbrar a adoção de medidas ambientais que não sejam impostas legalmente ou que não agreguem valor ao produto (Souza et al., 2013).

Tanto é que a ideia inicial do setor produtivo de que a adoção de ações ambientais pelas empresas era apenas uma despesa, e que o simples envio de resíduos para reciclagem ou o reflorestamento de uma área eram suficientes para a empresa ser considerada sustentável, está atualmente superada. Há anos, muitas empresas de destaque no mercado internacional investem em projetos de ecoeficiência e produtos verdes de forma lucrativa, corroborando ser possível a "conciliação do desenvolvimento econômico com a preservação ambiental" (Leite et al., 2013, p. 101).

Destarte, o setor produtivo tem buscado inúmeras alternativas para a adoção de medidas de gestão ambiental preventiva, muitas vezes alterando todo um processo de produção a fim de buscar a produção sustentável. Sem dúvida, a redução dos custos envolvidos na produção é um dos maiores benefícios visados pelo setor produtivo, seguido 
da observância das normas legais. Afinal, é notório o vácuo entre o desenvolvimento científico e a adoção de normas preventivas, sendo o princípio da precaução fundamental para a manutenção do equilíbrio entre essas duas realidades e diante da incerteza científica (Kriebel et al., 2001).

Uma das práticas que melhor representa as medidas de gestão ambiental preventiva é a observância da NBR para obtenção da Certificação ISO 14001:2015. Essa norma tem por objetivo a implementação de melhoria contínua do desempenho ambiental por meio de "resultados mensuráveis da gestão de uma organização sobre seus aspectos ambientais" (ABNT, 2015). Anorma prevê que ação preventiva é a ação para eliminar a causa de uma potencial não conformidade, sendo seus principais instrumentos a adoção de uma política ambiental interna da empresa, planejamento ambiental e implementação do SGA com a verificação das não conformidades, registro e adoção de ações corretivas. Esta forma de certificação e prevenção, apesar do custo para a empresa, mostra-se extremamente eficaz e tem tido ampla adoção no mercado. Conforme Moreira (2001), o SGA demonstra uma visão estratégica da empresa com reconhecimento de oportunidades de mercado devido à adoção destas medidas. A revisão da norma em 2015 contribuiu ainda mais para os processos de gerenciamento de risco ambiental, trazendo para dentro da norma conceitos de $\mathrm{ACV}$, antes previstos apenas em Norma específica - NBR 14040, referentes à avaliação de geração de impactos ambientais no decorrer de todas as cadeias produtiva, distributiva e consumerista, e redução de consumo de recursos naturais, por exemplo.

Todas estas ações têm como foco a prevenção da geração de resíduos na produção e na distribuição de produtos, utilizando o conceito consolidado pela PNRS de ecoeficiência, ou seja, visam à redu- ção do consumo de recursos naturais e do impacto da produção sobre o meio ambiente a fim de garantir a sobrevivência sustentável do planeta (PNRS, art. $\left.6^{\circ}, \mathrm{V}\right)$, observada a seguinte ordem, conforme o art. $9^{\circ}$, caput, da PNRS: "não geração, redução, reutilização, reciclagem, tratamento de resíduos sólidos e disposição final ambientalmente adequada dos rejeitos". Essas ações também visam à redução da periculosidade dos componentes perigosos, com a substituição por materiais menos perigosos e redução do volume de perigosos (Windham-Bellord et al., 2011, p. 186).

As empresas de adesivos, ao exercerem suas atividades produtivas, geram, inevitavelmente, um risco para o meio ambiente. Em suas atividades, estão incluídas diversas relações jurídicas com outras empresas, como para fornecimento de materiais, serviços, vendas de produtos, compras de componentes, etc. A relevância dada pela legislação ambiental à responsabilidade, tanto em nível nacional como global, exige que o setor produtivo de resíduos busque alternativas para prevenir essas responsabilidades em seus contratos jurídicos de compra e venda de produtos. Além das diversas ferramentas de gestão ambiental já examinadas, como a ACV, o SGA e as certificações, para uma eficiente gestão ambiental preventiva são necessárias ferramentas também de cunho jurídico. Ou seja, a fim de prevenir e resguardar responsabilidades, é fundamental que as empresas se valham de instrumentos como contratos e cláusulas contratuais que prevejam a observância das normas e políticas ambientais por seus fornecedores e clientes nas relações havidas com estes.

Muitas empresas já adotam cláusulas contratuais que preveem a obrigatoriedade de observância das normas ambientais, sendo, inclusive, cláusula contratual obrigatória no caso de empresas que possuem certificação ambiental. Ao celebrar con- 
tratos, principalmente de fornecimento, as empresas tendem a incluir cláusulas que ratifiquem a necessidade de compliance ambiental, obrigando-se a contratada, por exemplo, a: i) atender integralmente a legislação ambiental; ii) atender a Lei 12.846/13 (Lei Anticorrupção) e o Decreto 8.420/15 (que regulamenta a Lei 12.846/13) e ações para criação de uma cultura ética sustentável; iii) observar as boas práticas de gestão ambiental; iv) comprovar práticas de prevenção, fiscalização e controle das ações ambientais; v) aplicar, na consecução dos serviços, a melhor técnica disponível, dentro do atual estágio de desenvolvimento; vi) orientar, supervisionar e responder pela perfeita execução dos serviços prestados pelos seus funcionários.

O contrato é uma ferramenta jurídica que visa resguardar o contratante em caso de eventual responsabilização do contratado por dano ambiental no exercício exclusivo de sua atividade. Esse tipo de cláusula já tem, inclusive, aceitação na esfera judicial, pois a jurisprudência tem reconhecido sua validade, aceitando sua inobservância como justificativa para a rescisão contratual. Em um dos primeiros casos julgados pelo Superior Tribunal de Justiça sobre a matéria (Recurso Especial $n^{\circ}$ 1.208.486 - TO 2010/0151037-5), o Tribunal entendeu que:

[...] Bem de ver que a recorrente delimita a controvérsia, indicando a hipótese de quebra unilateral de contrato pela recorrida, bem como a existência de suposto negócio entre esta e outra empresa. Todavia, observa-se que o Tribunal de origem decidiu a controvérsia fundamentando que a recorrente não apresentou provas acerca da correta destinação ambiental das baterias usadas, conforme exigido pela legislação ambiental, firmando a seguinte conclusão, in verbis: "Portanto, nos exatos moldes do contrato praticado entre as partes deve a empresa apelante devolver sim o montante de carcaças das baterias usadas à fabricante, ora apelada, para que esta venha a cumprir com sua obrigação ao que dispõem as leis ambientais, posto que uma vez que tais baterias foram produzidas por esta então deve ela empregar destinação ambiental pertinente ao montante de componentes tidos como nocivos ao meio ambiente".

Especificamente, no tocante à pretensão de produção de outras provas, o Tribunal deixou assente que "evidenciou-se na presente celeuma que o descumprimento contratual foi provocado pela própria apelante, quando passou a vender as sucatas (baterias usadas) para um outro fabricante, inclusive concorrente da demandada. O fato foi assumido pela própria recorrente não somente na contestação como também no recurso aviado" (Brasil, 2011).

A inclusão de cláusulas contratuais que visam à observância de normas ambientais resguarda as partes contratantes. Na prática, em vista do alargamento da responsabilidade dos fabricantes e fornecedores consolidada pela PNRS, impede a efetiva utilização das excludentes obrigacionais, inclusive valendo-se do judiciário para tanto, sob pena de restar a empresa contratante responsabilizada solidariamente.

Portanto, resta evidenciado que existem diversos mecanismos de prevenção ambiental à disposição do setor produtivo e que, mesmo diante dos riscos inerentes à produção e ao desenvolvimento tecnológico, é possível, se não eliminar esses riscos, ao menos minimizá-los a fim de se obter o tão almejado desenvolvimento sustentável. O que não se admite mais é a degradação como mal necessário à produção.

Pode-se dizer que, apesar da peculiaridade que é característica intrínseca dos adesivos, ainda se denota pouca preocupação com o ciclo de vida dos adesivos no pós-consumo. As ações de gestão ambiental ainda são incipientes no que se refere ao ciclo de vida do produto como um todo, haja vista a peculiaridade dos adesivos, eis que este produto integra variados produtos finais, incorporando-se 
aos mesmos. Corolário deste fato é a dificuldade de adoção de medidas mais concretas no que se refere à responsabilidade compartilhada pelo ciclo de vida dos produtos. Por fim, indica-se a necessidade de ampliar ações efetivas de pesquisa e desenvolvimento de tecnologias mais limpas, como a utilização crescente de adesivos à base de água e hot melt nas empresas.

\section{Considerações finais}

Apesar de inegáveis avanços, a legislação ambiental brasileira ainda carece de agilidade para acompanhar os avanços tecnológicos, sobretudo diante do risco abstrato e dano futuro que tais avanços representam. Em uma queimada ou no desmatamento visualiza-se claramente o dano ambiental. Contudo, quando se trata de certos agentes químicos e físicos, é preciso contar com pesquisas transdisciplinares para comprovar os danos ou riscos ao meio ambiente e à saúde humana. $\mathrm{O}$ dano ambiental futuro e o risco abstrato são intangíveis, invisíveis e atemporais. É o caso dos adesivos, que, ao se incorporarem ao produto final, tornam-se intangíveis.

A PNRS, mesmo atribuindo a responsabilidade pelos danos a todos os envolvidos na produção e no consumo dos produtos, ainda carece de previsão específica no que se refere ao manejo e à disposição final de componentes que integram certos produtos, haja vista sua nocividade ao meio ambiente.

Com base no recorte proposto - indústria de adesivos -, critica-se a PNRS por ser parcialmente inócua, por sua falta de especificação técnica e diante da dificuldade decorrente da característica técnica do produto. Isto porque não há, até o presente momento, uma forma específica de controlar a destinação final de produtos que contenham adesivos em sua composição, ficando evidenciada a dificuldade de lidar com o risco abstrato e o dano futuro decorrentes da utilização de adesivos.

No caso da indústria de adesivos, a internalização das externalidades, ou seja, a assunção de responsabilidade do setor produtivo pelos resíduos sólidos provenientes da produção, até o final da cadeia de consumo, do ciclo de vida do adesivo, é a única forma viável de garantir um mínimo de qualidade ambiental sem onerar indevidamente a sociedade, diante da exacerbada geração de resíduos.

Somente através da internalização da sustentabilidade é que será possível afastar o fantasma do risco abstrato, sendo a observância de Normas ISO de desempenho ambiental, a adoção de medidas jurídicas - como exigências contratuais de compliance ambiental - e a fiscalização imprescindíveis para a efetiva prevenção ambiental.

\section{Referências}

ABNT - Associação Brasileira de Normas Técnicas. Norma Brasileira. ISO 14040:2009 Versão Corrigida: 2014. Disponível em: $<$ https://www.abntcatalogo.com.br/norma. aspx?ID=316462> . Acesso em: maio 2016.

ABNT - Associação Brasileira de Normas Técnicas. Norma Brasileira ISO 14.001:2015. Disponível em: <http://www.
abntcatalogo.com.br/norma.aspx?ID=936>. Acesso em: maio 2016.

Baumann, H.; Boons, F.; Bragd, A. Mapping the green product development field: engineering, policy and business perspectives. Journal of Cleaner Production, 10, 409-425, 2002. doi: 10.1016/S0959-6526(02)00015-X 
Beck, U. La sociedad del riesgo: hacia una nueva modernidad. Tradución de Jorge Navarro, Daniel Jiménez e Maria Rosa Borras. Barcelona: Paidós, 1998.

Beck, U. Sociedade de risco: rumo a uma outra modernidade. Traduzido por Sebastião Nascimento. São Paulo: Ed. 34, 2010.

Brasil. Lei $n^{\circ}$ 6.938, de 31 de agosto de 1981. Institui a Política Nacional do Meio Ambiente - PNMA. Brasília: DOU de 02/09/1981.

Brasil. Constituição da República Federativa do Brasil de 1988. Brasília: Senado Federal, DOU de 05/10/1988.

Brasil. Código Civil Brasileiro. Lei 10.406, de 10 de janeiro de 2002. DOU de 11/01/2002.

Brasil. Lei 12.305 de 02 de agosto de 2010. Institui a Política Nacional de Resíduos Sólidos - PNRS. Brasília: DOU de 03/08/2010.

Brasil. Superior Tribunal de Justiça. Acórdão no Recurso Especial $n^{\circ} 1.208 .486$ - TO (2010/0151037-5). Relator: Ministro Massami Uyeda. Julgado em 27 de maio de 2011.

Carson, R. Silent Spring. Nova Iorque: Houghton Mifflin Company, 1962.

Carvalho, D. W. A genealogia do ilícito civil e a formação de uma regulação de risco pela responsabilidade civil ambiental. Revista de Direito Ambiental, 65, 83-100, 2012.

EC - European Comission. Life cycle thinking and assessment for waste management. 2010. Disponível em: $<$ http://bookshop.europa.eu/en/life-cycle-thinking-and-assessment-for-waste-management-pbKH3109260/>.

Hauschild, M. Z.; Goedkoop, M.; Guinée, Z. J.; Heijungs, R.; Huijbregts, M.; Jolliet, O.; Margni, M.; Schryver, A. M. de; Humbert, S.; Laurent, A.; Sala, S.; Pant, R. Identifying best existing practice for characterization modeling in life cycle impact assessment. International Journal of Life Cycle Assessment. 18(3), 683-697, 2013. doi: 10.1007/ s11367-012-0489-5

Juarez, C.; Guereca, L.; Gassó, S. Análisis de ciclo de vida del sistema de gestión de resíduos municipales de la ciudad de México. In: Anais do I Simpósio Iberoamericano de Ingeniería de Resíduos. Catello, México, julho de 2008.

Kriebel, D.; Tickner, J.; Epstein, P.; Lemons, J.; Levins, R.; Loechler, E.; Quinn, M.; Rudel, R.; Shettler, T.; Stoto,
M. The precautionary principle in environmental science. Environmental Health Perspectives, 109(9), 871-876, 2001. Disponível em: $<$ http://www.ncbi.nlm.nih.gov/pmc/articles/ PMC1240435/pdf/ehp0109-000871.pdf>.

Leite, J. R. M.; Ayala, P. A. Direito Ambiental na sociedade de risco. Rio de Janeiro: Forense, 2004.

Leite, J. R. M.; Belchior, G. P. N. Dano ambiental na sociedade de risco: uma visão introdutória. In. Leite, J. R. M. (Coord.); Ferreira, H. S.; Ferreira, M. L. P. C. (Orgs.). Dano Ambiental na sociedade de risco. São Paulo: Saraiva, 2012.

Leite, D. S.; Pereira, M.; Leite, L. V. S. Breves notas da logística reversa como instrumento de evolução para o direito ambiental. Cadernos de Direito de Piracicaba, 13(24), 87-107, 2013. doi: 10.15600/2238-1228

Marques, J. L. S. Desenvolvimento de adesivos nanocompósitos de poliuretano à base de óleo de mamona. Porto Alegre, Dissertação (Mestrado em Engenharia de Minas, Metalurgia e de Materiais) - UFRGS, 2009.

Milaré, É. Direito do ambiente. 8. ed. São Paulo: Revista dos Tribunais, 2013.

Moreira, M. S. Estratégia e implantação de sistema de gestão ambiental modelo ISO 14000. Belo Horizonte: Desenvolvimento Gerencial, 2001.

Oliveira, C. L. de; Santos, C. H. M. dos; Bezerra, F. M. M.; Bezerra, M. M.; Rodrigues, L. de L. Utilização de adesivos de cianoacrilatos em suturas de pele. Revista Brasileira de Cirurgia Plástica, 25(3), 2010. Disponível em: <http:// www.scielo.br/scielo.php?script=sci_arttext\&pid=S1983$-51752010000300030 \& \operatorname{lng}=$ en\&nrm $=$ iso $>$.

Paiva, R. M. M. Composição e propriedades de produtos adesivos de base solvente. Aveiro, Portugal, Dissertação (Mestrado em Química Analítica e Controle de Qualidade) - Universidade de Aveiro, 2009.

Pinz, G. M. A responsabilidade ambiental pós-consumo e sua concretização na jurisprudência brasileira. Revista de Direito Ambiental, 65, 153-213, 2012.

Saldanha, P. M. Logística reversa: instrumento de solução para a problemática dos resíduos sólidos em face da gestão ambiental. Revista de Direito Ambiental, 65, 101-151, 2012.

Silva, S. A. Estudo do comportamento reológico dos adesivos hot melt PSA e sua relação com a composição e as 
propriedades adesivas. Porto Alegre, Dissertação (Mestrado em Engenharia) - UFRGS, 2008.

Souza, P.; Silva, F. L.; Bornia, A. C. Custos ambientais e logística reversa: uma análise sistêmica. Enfoque: Reflexão Contábil, 33(2), 119-135, 2013. doi: 10.4025/enfoque. v32i2.20346

Srivastava, S. K. Green supply-chain management: A stateof-the-art literature review. International Journal of Management Reviews, 9(1), 53-80, 2007. doi: 10.1111/j.1468$-2370.2007 .00202 . x$
Steigleder, A. M. Responsabilidade Civil Ambiental: as dimensões do dano ambiental no Direito Brasileiro. 2. ed. Porto Alegre: Livraria do Advogado, 2011.

Willers, C. D.; Rodrigues, L. B. A critical evaluation of Brazilian life cycle assessment studies. The International Journal of Life Cycle Assessment, 19(1), 144-152, 2014. doi: 10.1007/s11367-013-0608-y

Windham-Bellord, K. A.; Brandão e Souza, P. O caminho de volta, responsabilidade compartilhada e logística reversa. Revista de Direito Ambiental, 63, 181-202, 2011. 